\title{
Exposure to magnetic fields estimated from last job held in an electrical utility in Québec, Canada: a validation study
}

\author{
Dalsu Baris, Ben G Armstrong
}

\begin{abstract}
Objectives-To investigate how closely the variables of exposures to magnetic fields based on the last job held in an electrical utility in Québec, Canada, compared with those based on the workers' entire employment history with the company.

Methods-In large cohort studies, the last job held is often used to assign exposure to the study subjects. Exposure was assigned in this way for a mortality study of a cohort of electrical utility workers in Québec. For the present study, a sample of the cohort was used to compare the exposure estimates obtained from the last job with those obtained from full work histories.

Results-The correlations between indices based on the last job and on all jobs varied between 0.75 and 0.78 . The mean was slightly lower when only the last job was used. The last job was particularly good in identifying the most highly exposed people (for the exposure cut off point of 90th percentile for the last job and for all jobs, sensitivity $=0.69$, specificity $=0.97, \kappa=0.66$ ). The results suggest that although not all workers starting in highly exposed jobs stayed in them, it seemed that the workers who ended their working life in highly exposed jobs had stayed in these jobs throughout their working life.

Conclusion-The results indicated some (but not catastrophic) loss of information when estimates of exposure were based on the last job only.
\end{abstract}

(Occup Environ Med 1996;53:334-338)

Keywords: electromagnetic fields; exposure assessment; validity

It is desirable to obtain the most accurate estimate of exposure in occupational epidemiological studies. For occupational exposure to electric and magnetic fields, the best approach would be to obtain individual exposure data on each study subject by the use of personal dosimeters. However, this approach is not feasible for retrospective cohort studies or casecontrol studies. In these studies the usual approach is to use a job exposure matrix (JEM) to estimate individual exposures. A JEM consists of a list of job titles with a list of exposures corresponding to these job titles.
The ideal situation is to have an accurate JEM that included the variations in exposure over time for each job title, and also to have complete job histories for workers. One can then calculate the cumulative exposures of the workers by applying the matrix to the individual job histories.

However, in large cohort studies, complete work histories may not be readily available. Quite frequently the last job held is the only information that investigators can obtain, as in our cohort mortality study of 21744 electrical utility workers. ${ }^{1}$ This cohort, henceforth referred to as the Québec cohort, was one of three cohorts on which cancer incidence was investigated in the "Canada-France" casecontrol study. ${ }^{2}$

The objective of the present study was to investigate how closely the variables of exposures to magnetic fields based on the last job held in an electrical utility in Québec, Canada, compared with those based on the workers' entire employment history at the company. This was achieved by comparing in a sample of the Québec cohort, estimates obtained from only the last job with those obtained from the full work histories.

\section{Methods}

STUDY POPULATION

The Québec cohort consisted of all permanent male employees who had completed at least one full year of service in an electrical utility in the Province of Québec, Canada between 1970 and 1988 . The validity study subjects were the cancer cases and the controls selected for the Canada-France case-control study. The details of the case identification and the selection of controls are described elsewhere. ${ }^{2}$

\section{ESTIMATING EXPOSURE}

The complete occupational histories of the cancer cases and the controls had been abstracted from the company records for the Canada-France case-control study. ${ }^{2}$ A JEM was also developed for the Canada-France case-control study. The JEM rows consisted of grouped job titles with similar expected exposure to magnetic fields. Exposures to $60-\mathrm{Hz}$ magnetic fields were assessed for the grouped job titles from current exposure measurements made with the POSITRON exposure monitor (Positron Industries, Montréal, Québec, Canada) worn over a working week by a stratified random sample $(n=466)$ of workers. The entry in each row of the matrix was the arithmetic mean of the weekly arithmetic 
Table 1 Descriptive information on the study population $(n=1997)$

\begin{tabular}{lc}
\hline & Mean (range) \\
\hline Year of birth & $1924(1905-1960)$ \\
Year of hire & $1953(1920-1983)$ \\
Year of end of employment & $1983(1970-1988)$ \\
Year of death & $1981(1970-1988)$ \\
Total of years of employment & $26(1-51)$ \\
Age at diagnosis & $57(22-82)$ \\
\hline
\end{tabular}

Table 2 Correlation matrix between the estimates of exposure from the different approaches used $(n=1977)$

\begin{tabular}{|c|c|c|c|c|c|}
\hline \multirow[b]{3}{*}{ Approach used } & \multirow[b]{3}{*}{ Mean $(\mu T)$} & \multicolumn{4}{|c|}{ Correlation coefficient (r) } \\
\hline & & \multicolumn{2}{|c|}{ Cumulative exposure } & \multicolumn{2}{|c|}{ Mean exposure } \\
\hline & & All jobs & Last job & All jobs & Last job \\
\hline $\begin{array}{l}\text { Cumulative exp } \\
\text { All jobs } \\
\text { Last job }\end{array}$ & $\begin{array}{r}12 \cdot 14 \\
9 \cdot 73\end{array}$ & $\begin{array}{l}1.00 \\
0 \cdot 75\end{array}$ & $1 \cdot 00$ & & \\
\hline $\begin{array}{l}\text { Mean exposure } \\
\text { All jobs } \\
\text { Last job }\end{array}$ & $\begin{array}{l}0.47 \\
0.39\end{array}$ & $\begin{array}{l}0.86 \\
0.62\end{array}$ & $\begin{array}{l}0.66 \\
0.87\end{array}$ & $\begin{array}{l}1.00 \\
0.78\end{array}$ & 1.00 \\
\hline
\end{tabular}

means of all workers within the job category. For the details of the JEM, we refer the readers to the Canada-France case-control study. ${ }^{2}$

For the present study, the exposures of cases and controls to magnetic fields were estimated with four different approaches as described below.

(1) Cumulative exposure from all jobs. The cumulative exposure of each case and control was assessed by applying the JEM to the complete job histories. This approach was used by the Canada-France case-control study.

(2) Cumulative exposure from the last job. The last job held for a case means the job held at the time of the diagnosis (if the man was active when diagnosed) or the last job held in the company (if the man was retired or had left). For a control, it means the job held at the time of the diagnosis of the corresponding case, or the last job held. The cumulative exposure was calculated as in (1), except that it was assumed that each man held the same job (his last job) throughout his employment in the company. Thus, the cumulative exposure of each man was computed by applying the JEM to the last job held and multiplying

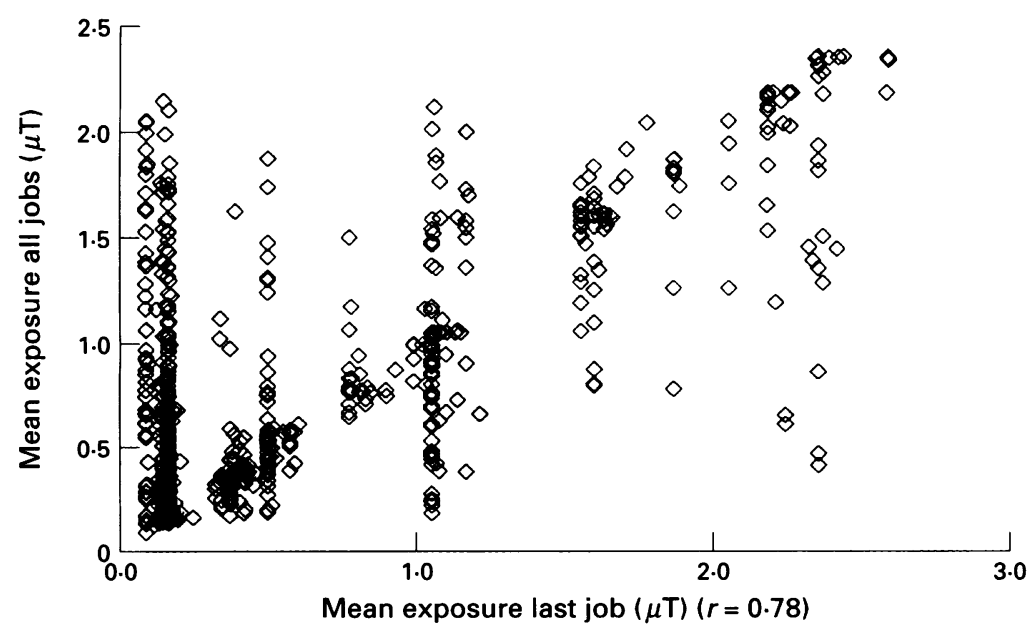

Figure 1 Agreement between measures of exposure to magnetic fields; mean of all jobs $v$ last job. this value by the man's total years of service in the company.

(3) Mean exposure from all jobs. The mean exposures were calculated by dividing the cumulative exposure from all jobs by the total years of service.

(4) Mean exposure from last job. This approach was used in the Québec cohort mortality study and involved simply assigning the value in the JEM for the last job.

\section{STATISTICAL ANALYSIS}

The main goal of the analysis was to find the extent of agreement between the different approaches in estimating individual exposure and identifying the exposed subjects for analysis in which subjects are grouped by exposure. First, the correlation coefficients between the four different approaches of exposure assessments were calculated. We then focused more detailed analysis specifically on the loss of information in relying only on the last job, rather than in choosing cumulative versus mean exposure. Because the mean exposure from the last job held was used for our cohort mortality study, ${ }^{1}$ we compared this with the mean exposure from all jobs, rather than comparing estimates of cumulative exposure.

We also calculated the sensitivity and specificity of methods based on the last job in identifying exposed subjects grouped by exposure. Exposure classification based on all jobs was taken as the working gold standard. Sensitivity is defined as the proportion of those who are truly exposed and are correctly classified as exposed by the last job held. Specificity is defined as the proportion of those who truly are not exposed and are correctly classified as not exposed by the last job held. The kappa $(\kappa)$ statistic was examined as a further measure of agreement. A $\kappa$ value of zero indicates a degree of agreement that would be expected by chance. The maximum value of $\kappa$ is unity and values of $\kappa$ greater than 0.50 are generally considered to represent good agreement. ${ }^{3-5}$

\section{Results}

Table 1 shows descriptive information for the study subjects.

Table 2 shows the means for the estimates of exposure from the four different approaches and the correlations between them. The means were about $20 \%$ lower when the last job was used. The correlations between equivalent indices based on the last job and on all jobs varied between $0 \cdot 75$ and $0 \cdot 78$. The poorest correlation was 0.62 , between the cumulative exposures from all jobs and the mean exposure from the last job. Figure 1 shows the agreement as a scatterplot between mean exposures for all subjects.

Table 3 shows the correlations between mean exposures based on the last job and on all jobs after division into groups of cases and controls, activity status, age at diagnosis, and duration of employment. The means of two indices are also given in each group. The pattern of slightly lower means when only the last job was used was consistent across groups: 
Table 3 Correlation between the mean exposures $(\mu T)$ to magnetic fields by case and activity status and by age at diagnosis

\begin{tabular}{|c|c|c|c|c|}
\hline & \multicolumn{4}{|l|}{ Mean } \\
\hline & $n$ & All jobs & Last job & $r(95 \% C I)$ \\
\hline All subjects & 1997 & 0.47 & $0 \cdot 39$ & $0.78(0.76-0.80)$ \\
\hline Cases & 774 & 0.48 & $0 \cdot 38$ & $0.76(0.73-0.79)$ \\
\hline Controls & 1223 & 0.47 & $0 \cdot 40$ & $0.80(0.78-0.82)$ \\
\hline $\begin{array}{l}\text { Activity status: } \\
\text { Active workers } \\
\text { Retired workers } \\
\text { Leavers }\end{array}$ & $\begin{array}{r}1136 \\
806 \\
55\end{array}$ & $\begin{array}{l}0.48 \\
0.47 \\
0.38\end{array}$ & $\begin{array}{l}0 \cdot 40 \\
0 \cdot 40 \\
0 \cdot 38\end{array}$ & $\begin{array}{l}0.77(0.75-0.79) \\
0.78(0.75-0.81) \\
0.99(0.98-0.99)\end{array}$ \\
\hline $\begin{array}{l}\text { Age at diagnosis: } \\
<45 \\
\quad 45-64 \\
\geqslant 65\end{array}$ & $\begin{array}{r}360 \\
1034 \\
603\end{array}$ & $\begin{array}{l}0.51 \\
0.46 \\
0.47\end{array}$ & $\begin{array}{l}0.42 \\
0.37 \\
0.41\end{array}$ & $\begin{array}{l}0.82(0.78-0.85) \\
0.76(0.73-0.78) \\
0.79(0.76-0.82)\end{array}$ \\
\hline $\begin{array}{l}\text { Duration of employ } \\
<10 y \\
10-19 y \\
\geqslant 20 y\end{array}$ & $\begin{array}{r}235 \\
375 \\
1387\end{array}$ & $\begin{array}{l}0.44 \\
0.44 \\
0.49\end{array}$ & $\begin{array}{l}0 \cdot 43 \\
0 \cdot 40 \\
0 \cdot 38\end{array}$ & $\begin{array}{l}0.95(0.94-0.96) \\
0.84(0.81-0.87) \\
0.74(0.72-0.86)\end{array}$ \\
\hline
\end{tabular}

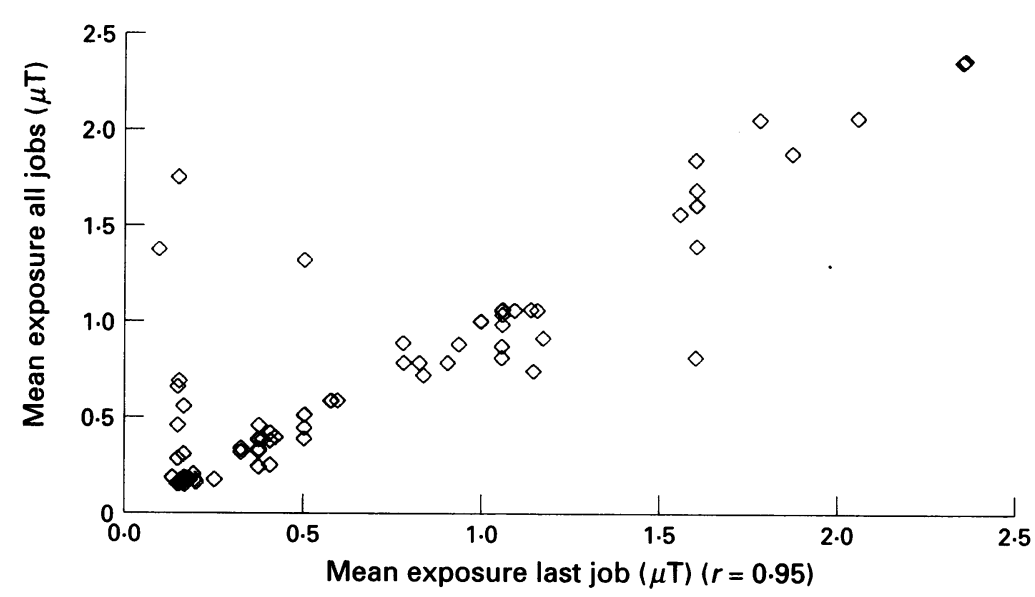

Figure 2 Agreement between measures of exposure to magnetic fields; mean of all jobs $v$ last job ( $\leqslant 10$ years employment).

cases and controls; active, retired workers, and leavers; or workers in each group of age at diagnosis (age $<45,45-64, \geqslant 65$ ), and for duration of employment (in years $<10$, $10-19, \geqslant 20$ ). However, the means were very close for the two methods in the following two groups: workers with duration of employment less than 10 years and leavers.

Table 4 Proportion of working life spent in the last job and the proportion of workers who spent $100 \%$ of their working life in their last job

\begin{tabular}{|c|c|c|c|c|c|}
\hline \multirow[b]{2}{*}{ Last job } & \multirow[b]{2}{*}{$n^{*}$} & \multirow{2}{*}{$\begin{array}{l}\text { Working life } \\
\text { spent in the } \\
\text { last job (\%)† }\end{array}$} & \multirow{2}{*}{$\begin{array}{l}\text { Workers who } \\
\text { spent all of } \\
\text { their working } \\
\text { life in their } \\
\text { last job (\%) } ¥\end{array}$} & \multicolumn{2}{|c|}{ Mean exposure $(\mu T)$} \\
\hline & & & & All jobs & Last job \\
\hline $\begin{array}{l}\text { Background exposure jobs: } \\
\text { White collar jobs } \\
\text { Blue collar jobs }\end{array}$ & $\begin{array}{l}824 \\
284\end{array}$ & $\begin{array}{l}79 \\
60\end{array}$ & $\begin{array}{l}52 \\
43\end{array}$ & $\begin{array}{l}0 \cdot 26 \\
0 \cdot 30\end{array}$ & $\begin{array}{l}0 \cdot 16 \\
0 \cdot 15\end{array}$ \\
\hline $\begin{array}{l}\text { Hydroelectric generation: } \\
\text { Equipment mechanics } \\
\text { Equipment electrician } \\
\text { Operator }\end{array}$ & $\begin{array}{l}40 \\
17 \\
32\end{array}$ & $\begin{array}{l}86 \\
93 \\
76\end{array}$ & $\begin{array}{l}62 \\
65 \\
31\end{array}$ & $\begin{array}{l}0.80 \\
0.98 \\
1 \cdot 54\end{array}$ & $\begin{array}{l}0.77 \\
0.92 \\
1.56\end{array}$ \\
\hline $\begin{array}{l}\text { Substation: } \\
\text { Equipment electrician } \\
\text { Maintenance worker }\end{array}$ & $\begin{array}{r}32 \\
104\end{array}$ & $\begin{array}{l}81 \\
92\end{array}$ & $\begin{array}{l}53 \\
70\end{array}$ & $\begin{array}{l}2.03 \\
1.00\end{array}$ & $\begin{array}{l}2.36 \\
1.05\end{array}$ \\
\hline $\begin{array}{l}\text { Distribution: } \\
\text { Linemen (contact and hot stick) } \\
\text { Meter installer } \\
\text { Meter reader }\end{array}$ & $\begin{array}{r}152 \\
35 \\
32\end{array}$ & $\begin{array}{l}92 \\
52 \\
70\end{array}$ & $\begin{array}{l}70 \\
17 \\
44\end{array}$ & $\begin{array}{l}0 \cdot 38 \\
0 \cdot 38 \\
0 \cdot 19\end{array}$ & $\begin{array}{l}0 \cdot 37 \\
0 \cdot 42 \\
0 \cdot 17\end{array}$ \\
\hline Transmission linemen & 22 & 89 & 59 & 0.59 & 0.60 \\
\hline
\end{tabular}

*Included only if $\mathrm{n} \geqslant 15$

†Proportion of working life spent in the job category in which the workers were classified based on their last job.

¥Proportion of workers who spent $100 \%$ of their working life in the job category in which they were classified based on their last job.
Correlations between two approaches were high in all groups. The highest correlation was among leavers $(r=0.99)$ and workers with less than 10 years of employment $(r=0.95$, fig 2). This is not surprising as these workers were likely to have held the same job throughout their time at the company.

Table 4 shows (a) the mean proportion of the subjects' total working lives at the company spent in that job; $(b)$ the proportion of the subjects who spent all of their working lives in that job; (c) the mean exposure calculated from all jobs; $(d)$ the mean exposures calculated from the last job, separately for groups of workers according to the JEM job category of the last job that they had.

In general men ending in highly exposed jobs (equipment electricians, operators, maintenance workers, linemen) had spent a high proportion of their lives in those jobs. The highest mean proportion of working life spent in the last job was for those ending as equipment electricians (hydroelectric generation) (93\%). Sixty five per cent of these workers spent all of their working life in that job.

The mean exposure from all jobs and the mean exposure from the last job were generally very close for men in highly exposed last jobs. This is consistent with the observation that men ending up in these jobs had spent most of their lives in them. For white collar and blue collar jobs classified to start with as unexposed, however, the mean exposure from all jobs was considerably higher than the exposure from the last job. This indicated that some of the workers who held unexposed last jobs, had previously held exposed jobs.

Overall, the results in table 4 indicate that although not all workers starting in highly exposed jobs stayed in them, it seemed that the workers who ended their working life in highly exposed jobs had stayed in these jobs throughout their working life. Workers did not usually move to jobs with high exposure late in their working life.

Table 5 shows the sensitivity, specificity, and $\kappa$ statistic as quantitative indices of accuracy (validity) and agreement for assessing the exposure, defined now as a dichotomy, from the last job held. The calculations were repeated for several different cut off points defining exposure. For the last job held, the cut off points of $0.16,0.49$, and $1.55 \mu \mathrm{T}$ were chosen because they were used in the Québec cohort mortality study to define exposure groups. ${ }^{1}$ Because of the lower mean exposure from the last job than that from all jobs, use of the same cut off points $(0.16,0.49$, and $1.55 \mu \mathrm{T})$ to define groups according to mean based on all jobs leads to very different proportions of subjects exposed. We therefore also compared classifications based on the last job from the cut off points $0 \cdot 16,0.49$, and $1.55 \mu \mathrm{T}$ with those of all jobs from cut off points that gave the same proportion exposed as with the last jobs. We also show agreement according to cut off points at the median, 75 th, and 90th percentiles of exposure values.

Sensitivity ranged from $59 \%$ to $70 \%$, specificity from $67 \%$ to $99 \%$, and $\kappa$ from $36 \%$ to 
Table 5 Sensitivity, specificity, and $\kappa$ statistics

\begin{tabular}{|c|c|c|c|c|c|c|c|c|c|c|c|}
\hline \multirow{2}{*}{\multicolumn{2}{|c|}{ Cut off points }} & \multicolumn{5}{|c|}{ Subjects (n) } & \multirow[b]{3}{*}{ Sensitivity } & \multirow[b]{3}{*}{ Specificity } & \multirow[b]{3}{*}{$\kappa$} & \multirow{2}{*}{\multicolumn{2}{|c|}{ Exposed (\%) }} \\
\hline & & \multirow{2}{*}{$\begin{array}{l}\text { Last job: } \\
\text { All jobs: }\end{array}$} & \multirow{2}{*}{$\begin{array}{l}E \\
E\end{array}$} & \multirow{2}{*}{$\begin{array}{l}E \\
N E\end{array}$} & \multirow{2}{*}{$\begin{array}{l}N E \\
E\end{array}$} & \multirow{2}{*}{$\begin{array}{l}N E \\
N E\end{array}$} & & & & & \\
\hline Last job & All jobs & & & & & & & & & Last job & All jobs \\
\hline $\begin{array}{l}>0.16 \mu \mathrm{T}^{\star} \\
>0.16 \mu \mathrm{T} \\
>0.49 \mu \mathrm{T}^{\star} \\
>0.49 \mu \mathrm{T} \\
>1.55 \mu \mathrm{T}^{\star} \\
>1.55 \mu \mathrm{T} \\
>\text { Median } \\
>\text { 75th percentile } \\
>\text { 90th percentile }\end{array}$ & $\begin{array}{l}>0.16 \mu \mathrm{T} \\
>65 \text { th percentilet } \\
>0.49 \mu \mathrm{T} \\
>83 \text { rd percentilet } \\
>1.55 \mu \mathrm{T} \\
>90 \text { th percentilet } \\
>\text { Median } \\
>75 \text { th percentile } \\
>\text { 90th percentile }\end{array}$ & & $\begin{array}{r}646 \\
492 \\
325 \\
236 \\
87 \\
82 \\
673 \\
335 \\
138\end{array}$ & $\begin{array}{r}46 \\
200 \\
26 \\
115 \\
26 \\
31 \\
327 \\
164 \\
62\end{array}$ & $\begin{array}{r}448 \\
209 \\
21 \\
104 \\
48 \\
39 \\
236 \\
165 \\
61\end{array}$ & $\begin{array}{r}857 \\
1096 \\
1435 \\
1542 \\
1836 \\
1845 \\
671 \\
1333 \\
1736\end{array}$ & $\begin{array}{l}0 \cdot 59 \\
0 \cdot 70 \\
0 \cdot 60 \\
0 \cdot 70 \\
0 \cdot 64 \\
0 \cdot 68 \\
0 \cdot 67 \\
0 \cdot 67 \\
0 \cdot 69\end{array}$ & $\begin{array}{l}0.95 \\
0.84 \\
0.98 \\
0.93 \\
0.99 \\
0.98 \\
0.67 \\
0.89 \\
0.97\end{array}$ & $\begin{array}{l}0.52 \\
0.55 \\
0 \cdot 65 \\
0.58 \\
0.67 \\
0.44 \\
0.36 \\
0.56 \\
0.66\end{array}$ & $\begin{array}{r}35 \\
35 \\
17 \\
17 \\
6 \\
6 \\
50 \\
25 \\
10\end{array}$ & $\begin{array}{r}55 \\
35 \\
27 \\
17 \\
7 \\
6 \\
50 \\
25 \\
10\end{array}$ \\
\hline
\end{tabular}

$\mathrm{E}=$ exposed; $\mathrm{NE}=$ non-exposed.

*The cut off points of $0.16 \mu \mathrm{T}, 0.49 \mu \mathrm{T}$, and $1.55 \mu \mathrm{T}$ were used in a cohort mortality study of electrical utility workers to define the background, above background medium, and above background high categories of exposure.

†For all jobs, the cut off points were chosen to obtain the same proportion of workers in the exposed categories for both approaches.

$67 \%$. The highest accuracy was obtained when we used the cut off point of the 90 th percentile for the last job and for all jobs (sensitivity $=$ 0.69 , specificity $=0.97, \kappa=0.66$ ).

\section{Discussion}

Accuracy and agreement between the different approaches in estimating exposure to magnetic fields were assessed in a sample of a cohort of electrical utility workers in Québec. The main purpose of this study was to compare a practical method of exposure assessment against a better but less practical method. In particular, we wished to validate the use of the last job held in our historical cohort mortality study ${ }^{1}$ because it was not feasible to abstract the complete occupational histories for all 21744 members of the cohort. In this discussion, we first consider the implications of our results for the interpretation of our cohort study, then the possiblity of generalising these results from the last job to other studies.

Our results showed high specificity of the methods based on the last job in identifying exposed subjects: a high proportion of those workers truly not exposed were correctly classified as unexposed, so that those classified as exposed were indeed exposed. Sensitivity of the last job method in identifying exposed subjects by grouping by exposure was lower: a significant proportion of those workers truly exposed were not classified as such, so that some of those classified as unexposed were actually exposed (table 4). These results indicate that although use of the last job resulted in loss of information in our cohort study, this loss did not invalidate the study.

Alderson $^{6}$ discussed the possible biases from use of the last occupation recorded at death registration as an indication of occupational exposures during a working life. $\mathrm{He}$ drew attention to the fact that the onset of occupational disease can result in changing job. His argument was that the worker's mobility might be related to his ill health from his occupational exposure. If this results in removal from the exposure by moving from heavy and exposed jobs to lighter unexposed jobs, the effect of exposure would be lost in the analysis when the last job was used to assign exposure especially if the exposure of interest was related to the health effect that caused the change of job. The obvious consequence of this would be the underestimation of the risk. In the electrical industry, the exposed jobs are highly skilled and active ones. If exposure to electromagnetic fields were associated with ill health, workers in the highly exposed jobs which usually demand high physical activity, might remove themselves from exposure by moving to less demanding unexposed jobs. This would result in some differential misclassification when the last job was used in assessing exposure in this industry if the ill health led to the death. It is unlikely that this problem occurred in our mortality study for cancer, which is not usually preceded by disabling morbidity. It remains as a concern for the causes of death which may be preceded by disability.

The use of all jobs is clearly better than the use of last job. However, this does not make the use of all jobs a perfect measurement, a true gold standard. Wacholder $e t a l^{7}$ used the term of "alloyed gold standard" for a good method of measurement that nevertheless had measurement error. They noted that the correlation between an approximate and alloyed gold measurement will be different from that between an approximate and true gold standard. The difference depends on the extent of error in the alloyed gold standard and size of correlation of errors in the approximate measure studied. We do not know how the error in the imperfect measurement (last job) and in the alloyed gold standard (all jobs) are correlated in our cohort study. However, it is likely that these errors were positively correlated as we used the same JEM for the two measurements.

One source of error in both our gold standard and approximate measure was the change over time in exposure in the same job which was not allowed for in either. In fact, the JEM used for the Canada-France case-control study ${ }^{2}$ allowed for the variation of exposure in the past. However, a preliminary analysis showed that the estimates corrected for differences in exposure in the past were very highly correlated with the estimates that were not so corrected $(r>0.90)$. Therefore for simplicity, we only used the uncorrected estimates, thereby focusing on the loss of information in relying on only last job rather than on correcting for changes in levels of exposure in the past. 
The last job held has been used in other occupational cohort studies of workers, in particular in one of telephone company workers, exposed to electric and magnetic fields. ${ }^{8}$ As a part of her study, Matanoski evaluated the use of the last job. Her results were broadly similar to ours. There was $85 \%$ agreement between the last job and the longest job held in her study. The reason for the similar findings in the two studies could be that in both industries the exposed jobs require skills, so that if the workers ended up in the skilled jobs, they are likely to have stayed in them. Thus we conjecture that use of the last job is a good method to assess exposure in electrical industries where the exposed jobs are also skilled jobs.

Ideally, for the studies of health effects of electromagnetic fields, exposure indices should be selected to match the mechanisms by which the biological effects are expected to occur. Various indices of exposure have been proposed, including the mean, maximum, proportion of time within a window or over a threshold level, and variability. Unfortunately, there is little knowledge from which to decide which is appropriate. A comparison of alternative indices of a week's exposure in a sample of electrical utility workers found high correlations between most of them. ${ }^{9}$ In any case, choice of index for summarising exposures over a week is unlikely to affect the validity of use of the last job to indicate exposure. However, choice of index for lifetime exposure might do so. For example, the last job would clearly provide a better indication of recent past exposure than of distant exposure, such as would be relevant under an assumption of a minimum latency of several decades. We did not investigate such indices, but we did find that the performance of the last job in identifying cumulative exposure was similar to that in identifying mean exposure (table 2).

Use of the last job causes bias and power loss due to imprecision in the exposures, but this is compensated by lower costs, or power gained by being able to include more subjects. The choice involves assessing this trade off. It is possible to formally compare statistical efficiencies allowing for costs, ${ }^{10}$ but an informal argument often suffices. In our cohort mortality study, we estimate that ascertaining complete work histories for all subjects would have cost over $\$ 50000$. We judged that this expense was unjustified, given that for diseases of specific interest (cancers and suicide), nested case-control and case-cohort studies have been undertaken. This strategy concentrated on the expensive process of abstracting complete work histories on those subjects who were most influential in the estimation of the most important associations, but still allowed less powerful investigations of other diseases from the last job. If we assume a correlation of 0.8 (table 2) between the true and approximate measure based on the last job, the power of the study from last job is equivalent to that in a study that used an accurate exposure measure with $36 \%$ fewer $\left(1-0 \cdot 8^{2}\right)$ study subjects. ${ }^{11}$

In conclusion, the results indicated some (but not catastrophic) loss of information when estimates of exposure were based on the last job only. The last job was particularly good for identifying the most highly exposed men, at least in this particular industry. A decision on whether the use of the last job to assess exposure is a sensible compromise between cost and precision requires the investigator's judgement based on the knowledge of job mobility, processes, and exposures in the industry considered.

This study was funded by a grant from the National Health Research and Development Programme of the Department of Health Canada, Ottawa. The Québec component of the Canada-France study which made this study possible was funded by Hydro-Québec. DB was a one year scholar of the funded by Hydro-Québec. DB was a one year scholar of the Institute de recherches en santé et en securite du travil du Québec. We thank Dr G Theriault for access to the data from the Canada-France study, and D Cyr, and M Ferron for their

1 Baris D, Armstrong B, Deadman J, Thériault G. A mortality study of electrical utility workers in Québec. Occup Environ Med 1996;53:25-31.

2 Thériault $G$, Goldberg $M$, Miller AB, Armstrong $B$ Guénel $P$, Deadmen J, Imbernon E. Cancer risks associated with occupational exposure to magnetic fields among electric utility workers in Ontario and Québec, among electric utility workers in Ontario and Quebec, 550-72.

3 Cohen J. A coefficient of agreement for nominal scales. Educational and psychological measurement 1960;20:37-46.

4 Cohen J. Weighted kappa: nominal scale agreement with provision for scaled disagreement or partial credit. Psychol Bull 1968;70:213-20.

5 Fleiss JL. Statistical methods for rates and proportions, 2nd ed. New York: John Wiley, 1981.

6 Alderson MR. Some sources of error in British occupational mortality data. $B r \mathcal{F}$ Ind Med 1972;29:245-54.

7 Wacholder S, Armstrong B, Hartge P. Validation studies using an alloyed gold standard. Am $\mathfrak{f}$ Epidemiol 1993;137: using an

8 Matanoski GM, Elliot EA, Breysse PN, Lynberg MC. Leukaemia in telephone linemen. Am F Epidemiol 1993; 137:609-19.

9 Armstrong BG, Deadman JE, Thériault G. Comparison of indices of ambient exposure to $60-\mathrm{Hz}$ electric and magnetic fields. Bioelectromagnetics 1990;11:337-47.

10 Armstrong BG. Study design for exposure assessment in epidemiological studies. Sci Total Environ 1995;168: 187-94.

11 Lagakos SW. Effects of mismodelling and mismeasuring explanatory variables on tests of their association with response variable. Stat Med 1988;7:257-74 